\title{
BMJ Open Global epidemiology of COVID-19 knowledge, attitude and practice: a systematic review and meta-analysis
}

\author{
Bodrun Naher Siddiquea (D) , ${ }^{1}$ Aishwarya Shetty, ${ }^{1}$ Oashe Bhattacharya, ${ }^{1}$ \\ Afsana Afroz, ${ }^{1,2}$ Baki Billah ${ }^{1}$
}

To cite: Siddiquea BN, Shetty A, Bhattacharya 0, et al. Global epidemiology of COVID-19 knowledge, attitude and practice: a systematic review and meta-analysis. BMJ Open 2021;11:e051447. doi:10.1136/ bmjopen-2021-051447

- Prepublication history and additional supplemental material for this paper are available online. To view these files, please visit the journal online (http://dx.doi.org/10.1136/ bmjopen-2021-051447)

Received 20 March 2021 Accepted 06 August 2021

Check for updates

(C) Author(s) (or their employer(s)) 2021. Re-use permitted under CC BY-NC. No commercial re-use. See rights and permissions. Published by BMJ.

${ }^{1}$ Department of Epidemiology and Preventive Medicine, School of Public Health and Preventive Medicine, Monash University, Melbourne, Victoria, Australia ${ }^{2}$ Centre of Epidemiology and Biostatistics, School of Population and Global Health, The University of Melbourne, Melbourne, Victoria, Australia

Correspondence to Dr Bodrun Naher Siddiquea; bodrun.naher@yahoo.com

\section{ABSTRACT}

Objective To assess the knowledge, attitude and practice (KAP) of the global general population regarding COVID-19. Design Systematic review and meta-analysis.

Methods MEDLINE, Embase, CINAHL and PsycINFO were used to identify articles published between 1 January and 30 June 2021 assessing KAP regarding COVID-19 in the global general population. The quality of eligible studies was assessed. Random effects model was used to obtain the pooled proportion of each component of KAP of COVID-19. Heterogeneity $\left(\mathrm{I}^{2}\right)$ was tested, and subgroup and correlation analyses were performed.

Results Out of 3099 records, 84 studies from 45 countries across all continents assessing 215731 participants' COVID-19 KAP were included in this study. The estimated overall correct answers for knowledge, good attitude and good practice in this review were $75 \%$ (95\% Cl $72 \%$ to $77 \%$ ), $74 \%$ (95\% $\mathrm{Cl} 71 \%$ to $77 \%$ ) and $70 \%$ (95\% Cl 66\% to 74\%), respectively. Low-income countries, men, people aged below 30 years and people with 12 years of education or less had the lowest practice scores. Practice scores were below $60 \%$ in Africa and Europe/Oceania. Overall heterogeneity was high $\left(I^{2} \geq 98 \%\right)$, and publication bias was present (Egger's regression test, $p<0.01)$. A positive significant correlation between knowledge and practice $(r=0.314, p=0.006)$, and attitude and practice $(r=0.348, p=0.004)$ was observed.

Conclusions This study's findings call for communitybased awareness programmes to provide a simple, clear and understandable message to reinforce knowledge especially regarding efficacy of the preventive measures in low and lower middle-income countries, and in Africa and Europe/0ceania, which will translate into good practice. Targeted intervention for men, people with low education, unemployed people and people aged below 30 years should be recommended. As most of the included studies were online surveys, underprivileged and remote rural people may have been missed out. Additional studies are needed to cover heterogeneous populations. PROSPERO registration number CRD42020203476.

\section{INTRODUCTION}

Emerging infectious diseases (defined as diseases that have "newly appeared in a population or have existed previously but are rapidly increasing in incidence or geographic range $^{, 1}$ ) have always been a public health

\section{Strengths and limitations of this study}

This is the first systematic review and meta-analysis that summarises existing knowledge, attitude and practice pertaining to COVID-19 in the global general population.

- The study identified a large number of studies and participants, covering all continents of the world.

- Articles published in non-English were excluded, and substantial heterogeneity was present in the evaluated outcomes.

- As most of the included studies were cross-sectional online surveys, underprivileged and remote rural people who do not have internet access may have been missed out.

threat worldwide. Since late December 2019, the world has been facing COVID-19, which is caused by SARS-CoV-2. On 30 January 2020, the WHO declared a state of public health emergency. Since then, this emerging and highly infectious disease has spread to 223 countries and territories, leading quickly to a global pandemic, with nearly 181.3 million cases and 3.9 million deaths reported as of 30 June 2021. At time of writing, COVID-19 is still challenging to contain for most countries around the world ${ }^{2}$ and it mainly affects the respiratory system and can lead to acute hypoxaemic respiratory failure, and 0.9\%$14 \%$ of these patients require admission to intensive care units (ICU) for advanced respiratory support. ${ }^{34}$ The consequent increase in critically ill patients with COVID-19 with respiratory failure has overwhelmed ICUs as well as the invasive mechanical ventilation capacity of healthcare systems in many countries across the globe.

Currently, vaccines are authorised and recommended to prevent COVID-19. Assuming two vaccine doses per person, according to a study published on 3 December $2020,^{5}$ an estimated 15.6 billion doses of COVID-19 vaccines are needed for the 194 
WHO member states to achieve a universal COVID-19 vaccination programme. Furthermore, 10.3 billion doses are required for targeted and high-risk groups. According to 12 COVID-19 vaccine manufacturers across the world, about 10 billion doses will be available by the end of 2021 . Vaccine production, however, is only the first step in a long delivery process that may face immense challenges such as logistics, cold chains and the actual administering of the vaccine. ${ }^{5}$ Furthermore, according to WHO, about $50 \%$ of the vaccine will be wasted because of temperature control in the supply chains. ${ }^{6}$ Therefore, distribution of vaccines, especially in rural and remote communities in many low to lower middle-income countries, requires strong international and national supply chains. ${ }^{5}$ In addition, the literature shows that vaccine hesitancy may affect the benefits of vaccination campaigns, ${ }^{7}$ and a recent global systematic review on COVID-19 vaccine hesitancy among general people showed that in many countries vaccine acceptance is below $60 \%{ }^{8}$

Thus, until the distribution of vaccine produces herd immunity, perceived risk-induced behaviours and preventive measures work best to stop the further spread of the disease. This includes behaviours like avoidance of crowded places, washing hands regularly or using hand sanitisers, avoiding frequent touching of the eyes, nose and mouth, cleaning touched surfaces frequently, wearing a mask, social distancing and seeking medical advice on noticing symptoms like sore throat, fever or shortness of breath. ${ }^{910}$ People need to follow these measures voluntarily for the safety of themselves and other people in general. The level to which they follow them voluntarily will depend on their accurate knowledge about the pandemic and their attitude towards it. ${ }^{11}$ However, since voluntary action is not enough, most governments across the world have been forced to come up with strict laws and measures that aim to stop the further spread of the disease. Still many countries across the world have not been successful in enforcing these laws. The biggest challenge with people's devotion to these control measures is determined by what they know about the disease, what their attitude is and what practices they undertake to follow their local measures.

Since the emergence of the virus, through the combined efforts of healthcare professionals and government bodies, several measures have been developed to raise awareness, improve knowledge and strengthen preventive practices to control the spread of infection. ${ }^{12}$ However, lack of knowledge about mode of transmission and vulnerable populations, as well as lack of attention to preventive measures, may still be widespread; consequently, many countries are facing localised spikes or the localised return of a large number of cases and deaths.

The constant evolving nature of the COVID-19 pandemic necessitates the need for regular update of scientific literature and research techniques. While reviews have been published in the past on knowledge, attitude and practice (KAP), they are not comprehensive and need timely update. One review article (that included

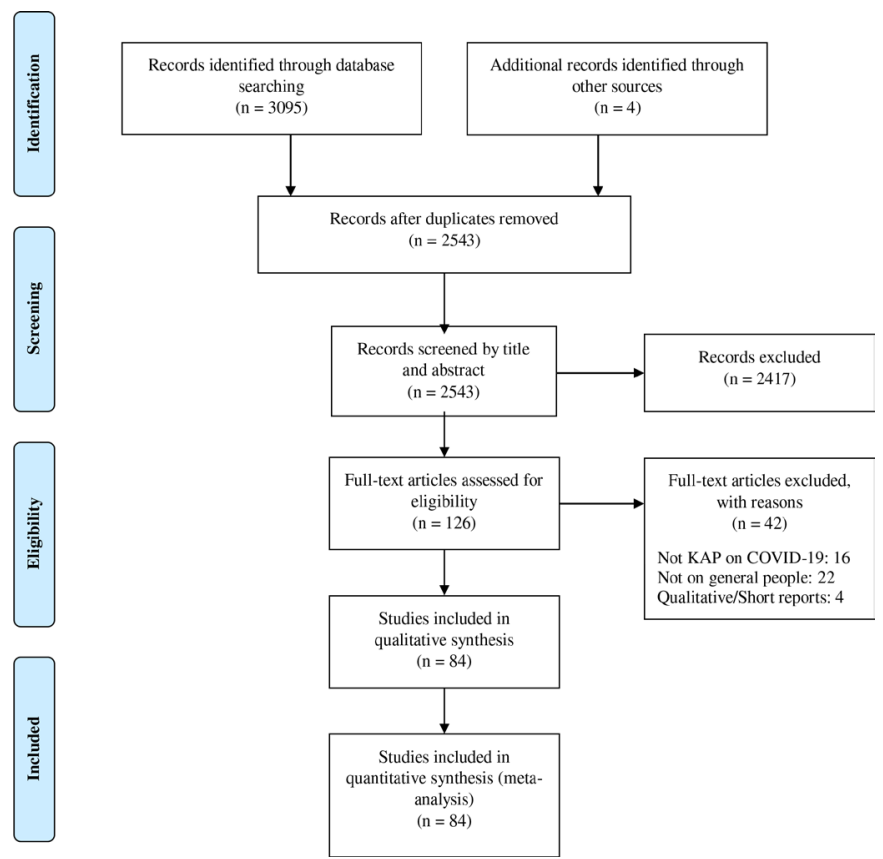

Figure 1 Preferred Reporting Items for Systematic Reviews and Meta-analyses (PRISMA) 2009 flow diagram. KAP, knowledge, attitude and practice.

articles published from December 2019 to September 2020) assessed predominantly the American subcontinent, and did not perform any definite or accurate quantitative analysis. ${ }^{13}$ Another review article that included articles from March to July 2020 also did not perform any meta-analysis and included studies conducted on healthcare workers as well as on the general population. ${ }^{14}$ Thus, the aim of the current study was to perform a systematic review and meta-analysis in order to provide the current global epidemiology of COVID-19 KAP in the general population. In comparison with the above published review studies, the present study was conducted over a more comprehensive time period (1 January 2020 to 30 June 2021) and performed a thorough meta-analysis with various in-depth subgroup analysis. To the best of our knowledge, the present study is the first global metaanalysis to have overall pooled prevalence of each component of KAP of COVID-19 among the global general population.

\section{METHODS}

This systematic review and meta-analysis was conducted in accordance with 'Preferred Reporting Items for Systematic Reviews and Meta-analyses' (PRISMA). ${ }^{15}$ It also complies with the Meta-analysis and Systematic Reviews of Observational Studies (MOOSE) guidelines. ${ }^{16}$ The study has been registered on PROSPERO. The review process is shown in the flow diagram in figure 1 and the PRISMA and MOOSE checklists are included as online supplemental tables 1 and 2. 


\section{Eligibility criteria}

Inclusion criteria

The review included studies that reported any form of quantitative assessment/measurement/evaluation of KAP regarding COVID-19 in the general population in any country or region across the world. There were no restrictions on the age, gender, ethnicity or health status of the participants, the duration for which the study was conducted or the geographic location of the study. Only published articles that had full text available (in English) were included.

\section{Exclusion criteria}

Studies were excluded if they were conducted only on some specific group of people, such as healthcare workers, medical students, pregnant women or people with comorbidities. Short reports, case reports, briefs, letters, editorials and study duplicates were also excluded.

\section{Search strategy, information sources and study selection}

With the help of a senior medical librarian, two authors (BNS and AS) independently searched the publicly available KAP in COVID-19-related published articles using databases of MEDLINE, Embase, CINAHL and PsycINFO following the PRISMA and MOOSE checklists (online supplemental tables 1 and 2). ${ }^{1516}$ This review also included preprints, which provide a dynamic update of research papers related to COVID-19. The main keywords for the search strategy included 'knowledge', 'attitude', 'practice' and 'COVID-19'. Only English-language articles were considered, as a search restriction. EndNote was used to store, organise and manage all the citations.

The same authors (BNS and AS) then independently conducted the initial screening of the title and abstract for each article obtained from the literature search. When a title or abstract was not sufficient grounds to reject an article, the full text was obtained and assessed. After the independent review, they had a disagreement with the consideration of four papers $(5 \%)$. Three papers were resolved by mutual consensus and one was resolved by consulting with the senior author (BB). Reference lists of the articles selected in this meta-analysis were also screened manually for any additional studies.

The preliminary search, which was carried out on 4 September 2020 and updated on 30 June 2021, covered published articles between 1 January 2020 (as the first novel case of COVID-19 was discovered on 31 December 2019) and 30 June 2021. The detailed search strategy is given in the online supplemental table 3 .

\section{Study outcomes}

This meta-analysis addressed three main outcomes of overall KAP pertaining to COVID-19 in the general population across the world.

Knowledge: level of knowledge or awareness regarding symptoms, mode of transmission, people at risk, incubation and isolation periods, virus fatality, treatments and prevention of COVID-19 infection.
Attitude: attitude towards controlling or managing of COVID-19.

Practice: practices such as hand hygiene, wearing face masks, social distancing, avoidance of crowded places/ social events and isolation/quarantine to prevent the spread of COVID-19.

The secondary outcomes included the estimated effect by age (under 30 years of age vs 30 or older), gender (male vs female), employment status (unemployed vs employed vs retired/student), income level of the country where the study was conducted (low income vs lower middle income vs upper middle income vs high income), educational level (up to 12 years vs over 12 years), continent and study period (January to March 2020 vs April to June 2020 vs July to October 2020).

\section{Data extraction}

Using a data extraction template (Excel spreadsheet), two reviewers (BNS and AS) independently extracted key information regarding identification of the study (authors, publication month, country where the studies were conducted), methodology (study setting, study design, study population, sample size, data collection tool, recruitment method, recruitment period), participants' demographics (gender, age, education, current employment status, income, area of residence) and main study findings (prevalence of correct knowledge/mean knowledge score of participants regarding symptoms, mode of transmission and prevention of COVID-19, prevalence of positive attitudes of participants towards controlling or managing of COVID-19 and prevalence of good practices such as social distancing, hand hygiene, wearing face masks and (where relevant) quarantine of participants to prevent COVID-19. The two data files were then cross-checked by a third reviewer (OB). Any disagreements were resolved by a consensus meeting under the supervision of a senior author (BB). Missing data, where required, were sought from the study authors.

\section{Quality assessment and risk of bias in individual studies}

The quality of the included studies was assessed by two independent reviewers (BNS and AS) using the National Heart, Lung, and Blood Institute (NHLBI) quality assessment tool for observational cohort and cross-sectional studies. ${ }^{17}$ The tool uses 14 criteria to assess internal validity and risk of bias. Each criterion was rated as 'yes', 'no', 'cannot determine', 'not applicable' or 'not reported' (online supplemental table 4). An overall quality of the study was then rated as good, fair or poor. Any discrepancies in the rating between the two reviewers were resolved by a third author $(\mathrm{OB})$.

\section{Data analysis}

Quantitative data (eg, percentage of KAP regarding COVID-19, and by age, gender, educational level, current employment status of the participants) extracted from each study were analysed by the author (AA) and were then cross-checked by the senior author (BB); any 
discrepancies were resolved. Statistical software package Stata V.16 (StataCorp, USA) was used for statistical analyses.

Means (SDs) or medians (25th and 75th percentiles), where appropriate, were extracted and then reported for numerical data. Percentage was extracted and then reported for each category of KAP, age group, gender, educational level and employment status of the study participants. The pooled proportion of COVID-19 KAP was calculated as a data synthesis of primary outcomes and was presented in forest plots. This analysis was performed using the random effects model, as this method demonstrates better properties in the presence of heterogeneity (if any), accounting for both within-study and betweenstudy variances. ${ }^{18}$ Heterogeneity among the included studies was tested using the $\chi^{2}$ test on Cochran's Q statistic, which was calculated by means of $\mathrm{H}$ and $\mathrm{I}^{2}$ indices. The $\mathrm{I}^{2}$ index represents the percentage of total heterogeneity across studies based on true between-study differences rather than on chance. $\mathrm{I}^{2}$ values over $75 \%$ might represent substantial/considerable heterogeneity. ${ }^{19}$ In order to identify the possible sources of substantial heterogeneity, subgroup analysis was conducted for each of the components of KAP by age group, gender, educational level, employment status, income level of the country, continent and study period. ${ }^{20}$ The income level of each country was classified as low income, lower middle income, upper middle income or high income, according to the World Bank. ${ }^{21}$ A comparison of China versus other countries was done because China was the epicentre of COVID-19, and was the first country to introduce the preventive measures and strict laws. Hence, we wanted to analyse if this difference in timeline would have an effect on its people's KAP in comparison with other countries. Egger's regression test was used to examine for publication bias, and the symmetry of the funnel plots was evaluated. ${ }^{22}$ Sensitivity analyses were performed using quality score categories of the included studies. Furthermore, correlation analysis among the components of KAP was also performed to evaluate the strength and direction of correlation (denoted by r) between knowledge and attitude, attitude and practice, and knowledge and practice.

\section{Patient and public involvement}

There was no patient or public involvement in this systematic review of published literature.

\section{RESULTS}

A total of 3099 articles, published between 1 January 2020 and 30 June 2021, were retrieved from the four databases and manual searches. After removing duplicate records and screening by titles and abstracts, 126 articles were included for full-text reading. Of these, 42 articles were excluded by the exclusion criteria. Finally, 84 studies from 45 countries or territories, reporting 215731 participants' KAP towards COVID-19, were included in the qualitative and quantitative analyses. ${ }^{11}{ }^{23-105}$ Of them, 66 were cross-sectional online surveys, 12 were community-based surveys, 5 were both community-based and online surveys and 1 was a hospital-based cross-sectional study. Based on the NHLBI quality assessment tool, 17 studies were of good quality, 44 were of fair quality and the remaining 23 were of poor quality. Online supplemental table 5 summarises the study features and the characteristics of the participants. The age of the study participants ranged from 16 to 75 years, and $41.7 \%$ were male. In the context of participants' education, $23.8 \%$ had up to secondarylevel education and $74.3 \%$ had university-level education. About $48.7 \%$ of participants were employed, $15.2 \%$ were unemployed, $14.3 \%$ were students and $3.5 \%$ were retired. In terms of country income level, $18 \%$ of the studies $(n=32$ $617)$ were from high-income countries, $30 \%(\mathrm{n}=63545)$ were from upper middle-income countries, $32 \% \quad(n=33$ $360)$ were from lower middle-income countries and $20 \%$ ( $n=13$ 293) were from low-income countries.

Figure 2 represents the pooled proportion of people who had answered correctly in their knowledge questions, had positive attitude and good practice techniques. The findings demonstrated that $75 \%$ of the present study population answered the knowledge question correctly (95\% CI $72 \%$ to $77 \%, \mathrm{p}<0.001, \mathrm{I}^{2}=99.55 \%$ ), $74 \%$ had positive attitude towards COVID-19 (95\% CI $71 \%$ to $\left.77 \%, \mathrm{p}<0.001, \mathrm{I}^{2}=99.58 \%\right)$ and $70 \%$ followed good COVID-19 practice techniques (95\% CI $66 \%$ to $74 \%$, $\left.\mathrm{p}<0.001, \mathrm{I}^{2}=99.69 \%\right)$. High heterogeneity was observed $\left(\mathrm{I}^{2}>99 \%\right.$ ), with the presence of publication bias (Egger's regression test, $\mathrm{p}<0.01)$. Correlation analysis among the components of KAP was also performed and is presented in online supplemental figure 1. Very weak and insignificant correlation of knowledge with attitude was observed. However, practice had a significant positive correlation with both knowledge $(\mathrm{r}=0.314, \mathrm{p}=0.006)$ and attitude $(\mathrm{r}=0.348, \mathrm{p}=0.004)$. Furthermore, practice measures pertaining to COVID-19 did not correlate with time since the emergence of this pandemic. Prevalence of each component of KAP by countries has been presented in figure 3 .

Online supplemental table 6 presents the subgroup analysis results by age group, gender, educational level, employment status, country income level, study period and continents. Respondents aged 30 years and above had relatively higher knowledge $(80 \%, 95 \%$ CI $75 \%$ to $85 \%$ vs $78 \%, 95 \%$ CI $74 \%$ to $83 \%)$, attitude $(73 \%, 95 \%$ CI $65 \%$ to $81 \%$ vs $68 \%, 95 \%$ CI $59 \%$ to $78 \%$ ) and practice $(82 \%, 95 \%$ CI $74 \%$ to $90 \%$ vs $80 \%, 95 \%$ CI $72 \%$ to $88 \%)$ compared with those aged below 30 . However, the difference was not significant as the respective CIs overlapped. There were no significant differences between male and female participants regarding KAP; however, practice scores were slightly lower among male participants $(75 \%$, $95 \%$ CI $69 \%$ to $80 \%)$ than females $(77 \%, 95 \%$ CI $72 \%$ to $82 \%$ ). Participants with 12 years of education or less had non-significant lower knowledge and practice than, but similar attitudes to, those with above 12 years of education. There was no significant difference between 

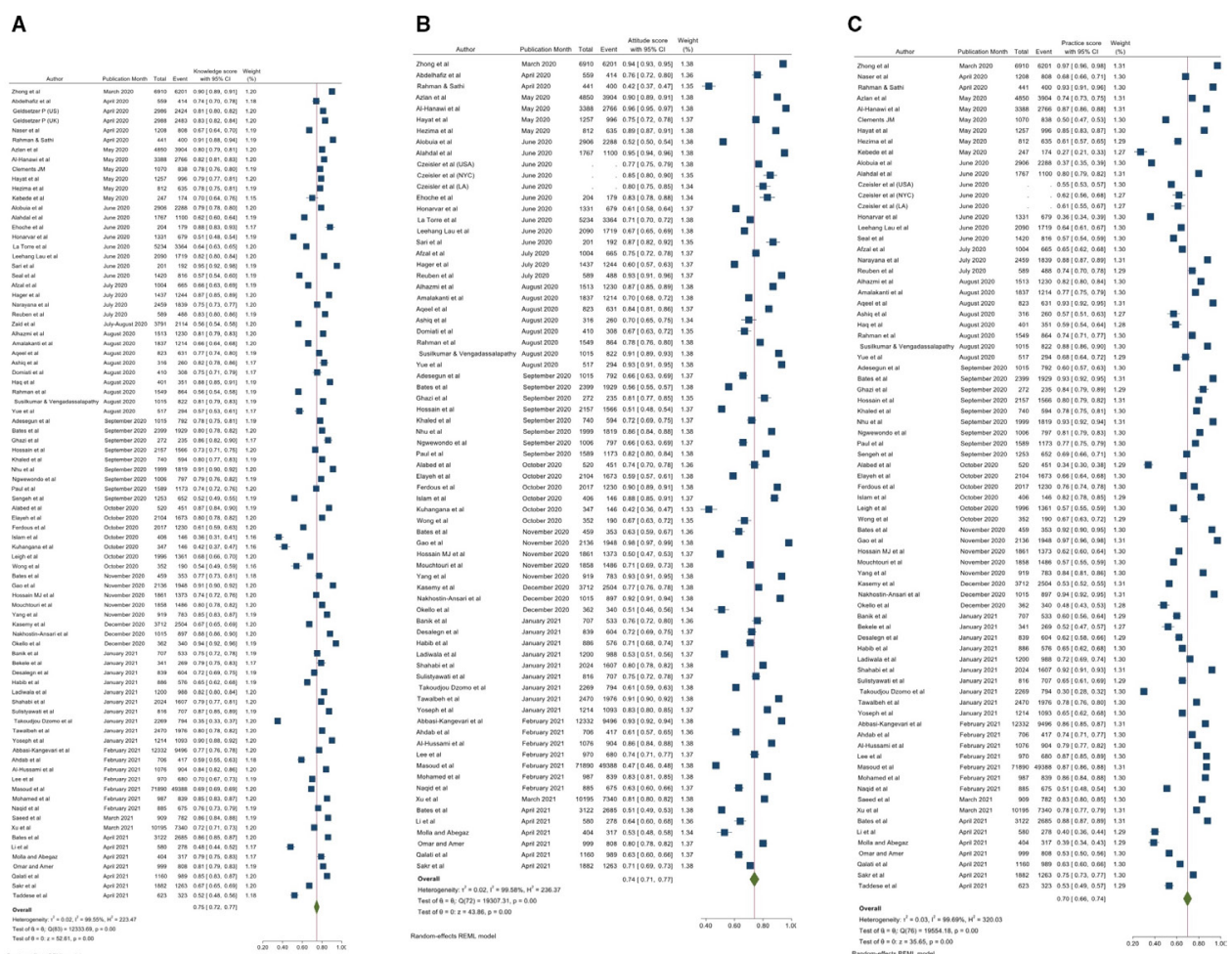

Figure 2 Pooled proportion of (A) knowledge, (B) attitude and (C) practice of COVID-19. REML-Restricted Maximum Likelihood

employed and unemployed participants when compared by each component of KAP. Knowledge score ranged from $72 \%$ (95\% CI $63 \%$ to $80 \%$ ) for low-income countries to $79 \%$ (95\% CI $75 \%$ to $83 \%$ ) for upper middle-income countries. There was no progressive increase or decrease in attitude and practice scores by income level. However, low-income countries had the lowest attitude score $(69 \%$, $95 \%$ CI $62 \%$ to $76 \%$ ) and that was the highest for upper middle-income countries ( $78 \%, 95 \%$ CI $72 \%$ to $84 \%)$. In the context of practising scores, low-income countries had the lowest (55\%, 95\% CI $46 \%$ to $64 \%$ ), and the highest came from the upper middle-income countries $(77 \%$, $95 \%$ CI $70 \%$ to $84 \%$ ) and the difference was statistically significant. Analysis by continent showed non-significant differences. However, Americas had the highest knowledge score $(79 \%, 95 \%$ CI $74 \%$ to $83 \%)$ and that was the lowest in Europe/Oceania (67\%, 95\% CI 54\% to 80\%). Attitude scores were highest in Middle East $(79 \%, 95 \%$ CI $72 \%$ to $85 \%$ ) and lowest in Americas $(66 \%, 95 \%$ CI $56 \%$ to $77 \%$ ). Asia had the non-significant highest practice score $(76 \%, 95 \%$ CI $71 \%$ to $81 \%)$ as compared with other continents. Further subgroup analysis was done by time of data collection (study period) into 3 months' interval (January to March 2020, April to June 2020, July to October 2020). There was no significant increase or decrease in knowledge and practice over time. However, positive attitude towards COVID-19 had been decreased significantly over the time (January to March 2020: 80\%, 95\% CI $74 \%$ to $86 \%$; April to June 2020: $73 \%$, 95\% CI $68 \%$ to $77 \%$; July to October 2020: $65 \%$, $95 \%$ CI $57 \%$ to $73 \%)$. Heterogeneity was high $\left(\mathrm{I}^{2}>98 \%\right)$ across all subgroup analyses (except for Europe/Oceania for attitude and practice where the heterogeneity was $0.29 \%$ and $0.28 \%$, respectively), and publication bias was present in most of the studies.

The analyses comparing KAP between studies from China versus other counties are illustrated in online supplemental figure 2. The KAP scores across five studies from China ( $\mathrm{n}=10482)$ reported an overall higher prevalence of each component of KAP of $79 \%$ (95\% CI $67 \%$ to $92 \%$ ), $92 \%$ (95\% CI $86 \%$ to $97 \%$ ) and $85 \%$ (95\% CI $74 \%$ to $96 \%$ ) as compared with studies from other countries of $74 \%$ (95\% CI $71 \%$ to $77 \%$ ), $72 \%$ (95\% CI $69 \%$ to $76 \%$ ) and $69 \%$ (95\% CI $65 \%$ to $73 \%$ ), respectively, which showed statistical significance for attitude and practice. Sensitivity analyses were performed by quality of the studies, as presented in online supplemental figure 3; however, high heterogeneity and presence of publication bias still existed.

Further analysis was also done on some important individual questions regarding KAP towards COVID-19, as illustrated in online supplemental table 7 . Of all participants, $85 \%$ and $81 \%$ had correct knowledge on 'main symptoms' (reported by 61 studies) and 'population at risk' (reported by 46 studies) of COVID-19, respectively, while $83 \%$ (reported by 58 studies) and $75 \%$ (reported by 39 studies) of respondents were aware of 'route of transmission' and spread of infection by asymptomatic patients, respectively. Knowledge regarding avoidance of crowded places as a preventive measure was reported by 27 studies, with overall correct knowledge of $95 \%$. Correct knowledge about 'isolation and treatment of 
A
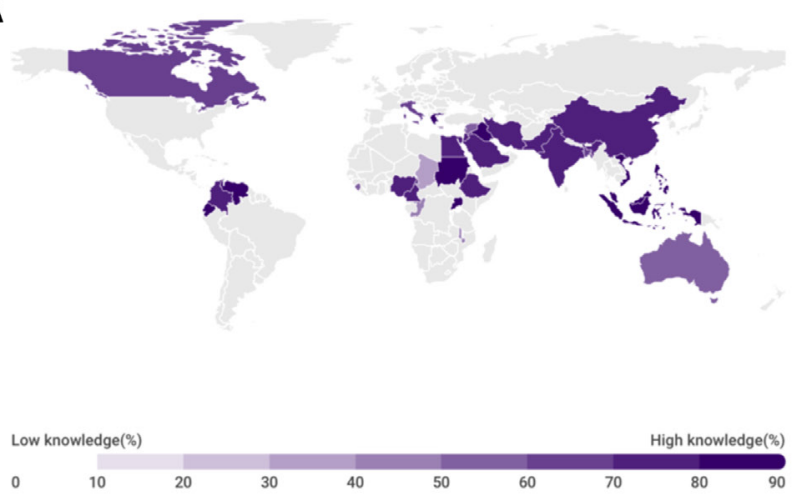

B

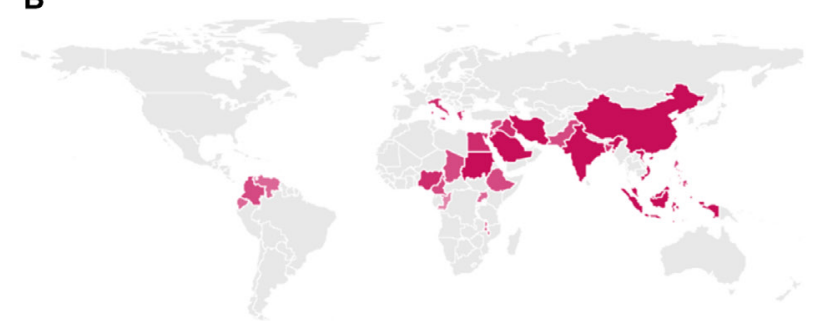

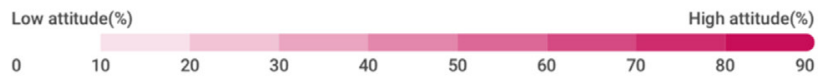

C

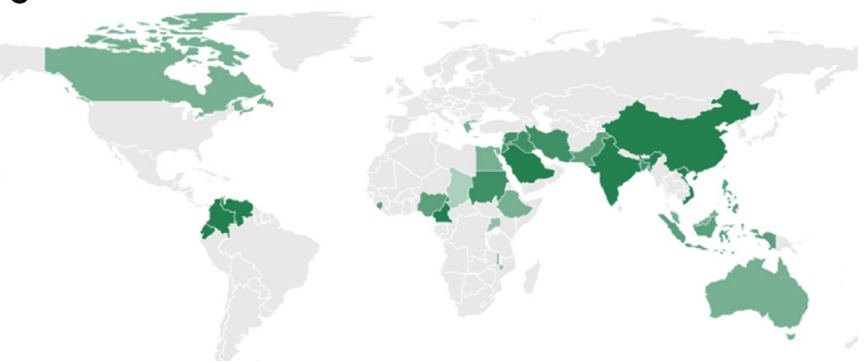

Low levels of good practice $(\%)$

$\begin{array}{llllllllll}0 & 10 & 20 & 30 & 40 & 50 & 60 & 70 & 80 & 90\end{array}$

Figure 3 Geographical representation of (A) knowledge, (B) attitude and (C) practice during the COVID-19 pandemic.

patients' (reported by 32 studies) and 'quarantine or incubation period' (reported by 44 studies) of COVID-19 was observed among $91 \%$ and $87 \%$ of the study participants, respectively. However, only $70 \%$ of the participants, reported in 35 studies, had correct knowledge about 'wearing a face mask' as a preventive measure.

Positive attitude towards 'successful control of COVID19' (reported by 22 studies) and 'social distance' (reported by 11 studies) was reported by $71 \%$ and $88 \%$ of the study participants, respectively.

Practising hand hygiene through 'proper hand washing or using hand sanitiser' was reported by $80 \%$ of the participants in 49 studies; $70 \%$ of the study participants (reported by 32 studies) maintained social distance, and $75 \%$ (reported by 45 studies) avoided crowded places or social events to prevent the spread of infection. Unexpectedly, only $65 \%$ of the participants (reported by 56 studies) were practising the wearing of face masks while going out. High heterogeneity was observed in all these subgroup analyses, and presence of publication bias was observed in most.

\section{DISCUSSION}

This is a large international systematic review and metaanalysis that has examined the KAP of the general population on the novel COVID-19. Data were compiled from 215731 participants from 84 studies of 45 countries, covering all continents. The study demonstrated a pooled score of $\geq 70 \%$ in each of the three components of KAP. The overall practice of preventive measures was low in the low-income countries, in Africa and Europe/Oceania, and among men, employed people and people aged 30 and above. There was a positive correlation between the components of KAP.

The estimated overall correct answers for knowledge, good attitude and good practice techniques in this review were $75 \%, 74 \%$ and $70 \%$, respectively. A study from H1N1 influenza A reported a lower knowledge (60\%) and similar attitude $(74.5 \%)$, but higher practice $(77.3 \%)$ scores, compared with current study. ${ }^{106}$ Studies from SARS-CoV in 2003 reported a knowledge score of 52.4\%$67.4 \%$ on symptoms among the general population compared with $85 \%$ in our study. ${ }^{107}$ Furthermore, a study from Saudi Arabia on Middle East respiratory syndrome (MERS) reported study participants' fair knowledge on symptoms $(79.8 \%)$ and transmissions $(90.6 \%)$, and their practice on 'washing hands frequently' (94\%) and 'using face masks' $(74.9 \%),{ }^{108}$ which were higher than those in the current study. This could be due to high-risk perception and their longer experience with MERS (as the study was conducted 2 years after the first appearance of MERS-CoV).

Subgroup analysis showed that overall knowledge score was low in the low and high-income countries, in Europe/ Oceania, among participants with 12 years or less education and unemployed people, and attitude score was low in Africa, Americas and low-income countries. Low practice score was observed in Africa, Americas, Europe/Oceania, the low-income countries, and among males, employed people, people aged below 30 years and participants with 12 years of education or less. A meta-analysis conducted among general population to see "the association between gender and protective behaviours in response to respiratory epidemics and pandemics' revealed that females are about $50 \%$ more likely than males to adopt or practise preventive behaviours (eg, hand washing, face mask use, avoidance of public transport).${ }^{109}$ Educational attainment may also have a direct effect on knowledge and consequently on practices as people with less education are less likely to adopt preventive measures. Population density, 
living conditions, livelihood and affordability could be the reasons behind low practices in the low-income countries. Moreover, due to existing health inequalities in low-income and lower middle-income countries and in socially disadvantaged groups, pandemics generally have their greatest effects on these populations. ${ }^{5}$ During the 1918 'Spanish' influenza pandemic and in the 2009 H1N1 influenza pandemic, racial minority/minority groups were most affected. ${ }^{110} 111$ However, literature supports that during COVID-19 pandemic, more cases and deaths have been reported from high-income and upper middle-income countries. ${ }^{5}$ These differences may be related to timing of transmission, countries' response patterns, availability and accuracy of tests, sociodemographic condition, countries' environmental factors and connectivity and trade patterns.

Analysis by study period showed no progressive increase or decrease in knowledge over time; however, the positive attitude towards COVID-19 had been decreased significantly over time (January 2020 to October 2020). A major reason for this may be attributed to pandemic fatigue where the prolonging timeline of the pandemic makes it harder to follow the COVID-19 prevention guidelines. Besides, a decrease in perceived susceptibility and perceived severity may further deteriorate the positive attitude towards the pandemic. ${ }^{112}$ The practice of COVID-19 prevention measures also did not increase since the emergence of this pandemic in early 2020, which may be partly reflected from the multiple spikes of COVID-19 spread in many countries across the world. This may be due to lack of understanding of the severity of the disease or true risk, low perceived risk of acquiring infection and perceived efficacy of the preventive measures.

Further subgroup analysis showed that overall KAP scores were higher (79\%, 92\% and $85 \%$, respectively) in the studies from China, the early COVID-19 epicentre, compared with studies from other countries $(74 \%, 72 \%$ and $69 \%$, respectively). This could be due to highly educated study participants in the study from Wuhan (over $80 \%$ had associate degrees or higher), overwhelming news by the media and public health authorities, their experience with previous SARS outbreak and strict actions taken by the local government to control the infection immediately after the outbreak.

In this current study, the overall score of knowledge regarding individual questions about main symptoms, population at risk, route of transmission of COVID-19, isolation and treatment of infected people and quarantine time was higher than $80 \%$; however, overall, $75 \%$ and $70 \%$ of respondents had knowledge of asymptomatic patients and the use of face masks as preventive measures, respectively. There were significant differences between knowledge and actual practices, and attitude and practices-specifically, avoidance of crowded places and maintaining social distance. Though $95 \%$ of participants had the knowledge of avoidance of crowded places to prevent the infection, only $75 \%$ of them were practising it. On the other hand, $88 \%$ of participants had a positive attitude to maintain social distance, only $70 \%$ of them were practising it. This difference could be due to lack of understanding of the preventive measures, the rationales for their use and their impact on health, and due to population density and livelihood. Studies from H1N1 influenza A reported correct knowledge on symptoms $(68.1 \%-76 \%)$, route of transmission $(56.3 \%-75.6 \%)$, use of face mask $(36.6 \%-70.4 \%)$, and practice of frequent hand washing $(54.6 \%-56.9 \%)$ and avoidance of crowded places $(42.9 \%-52.6 \%)$, which were lower than those in this current study. ${ }^{13-115}$ This could be due to low educational level (nearly $50 \%$ of study participants had below primary/middle school education), lack of perceived risk of spread of the disease and lack of perceived efficacy of various preventive measures among the H1N1 study participants.

A correlation analysis conducted in this study showed a positive relationship between components of KAP. Literature supports correlation between KAP in relation to health issues, which supports this study findings. ${ }^{116}$

A wide heterogeneity was observed in the reported prevalence of each component of KAP, with ranges of $35 \%-95 \%, 42 \%-96 \%$ and $27 \%-97 \%$, respectively. This was partly explained by the sociodemographic and cultural differences and political influence, and partly by the differences in the questionnaire contents, measurement and scoring systems. The majority of the studies were online surveys, and literature supports that gender, age and education influence online survey behaviour. ${ }^{27}$ Internet and social media are today's important online health information resources, hence their users may have gained more information than underprivileged population. Differences in the time and actions taken by the government, trust in the governing institutions and experience in management of previous outbreaks may have influenced the attitude of the participants. ${ }^{27} 344570$ Mixed messages about the use of face masks in public places, scarcity and affordability of face masks, cultural norms to shake hands and going to social, family or religious gatherings, continuity of water supply and hand washing facilities and living conditions may have contributed to adopt the preventive practices against COVID-19 infection. 334652117

This systematic review has several strengths and limitations. First, because of the challenges in conducting research during the pandemic, most of the studies were online surveys and covered major cities of the respected countries. Therefore, vulnerable population particularly income-poor people and urban slum dwellers, and people living in remote rural areas who did not have internet access may have missed out. Second, heterogeneity was high in the evaluated outcomes. Although a range of subgroup analyses have been performed, the sources of heterogeneity could not be identified. Third, articles published in other than English were excluded, which may have resulted in the exclusion of some studies. Despite these limitations, to our knowledge, this is the first systematic review and meta-analysis on KAP of COVID-19 
among global general population. Furthermore, the study identified a large number of studies and participants, covering all continents of the world, and provided meaningful data on the KAP of COVID-19 in the general population.

\section{CONCLUSION}

The overall KAP pertaining to COVID-19 in the general population in this study was $75 \%, 74 \%$ and $70 \%$, respectively. Low practice score was observed in Africa and Europe/Oceania, in low-income countries, and among men, employed, aged below 30 years, and participants with 12 years of education or less. These data suggest targeted group intervention to reinforce knowledge giving attention to efficacy of each of the preventive measures, which will translate into good practice. Additional studies covering heterogeneous population are also needed.

Contributors $B B, A A$ and BNS conceived the study and together with AS and $O B$ developed the protocol. BNS and AS did the literature search and selected the studies. BNS and AS extracted the data, and OB verified the data. $A A$ and $B B$ synthesised the data. BNS drafted the initial report with input from AS and BB. BNS, $A S, O B, A A$ and $B B$ critically revised the successive drafts of the paper. All authors approved the final version of the report.

Funding The authors have not declared a specific grant for this research from any funding agency in the public, commercial or not-for-profit sectors.

Competing interests None declared.

Patient consent for publication Not required.

Provenance and peer review Not commissioned; externally peer reviewed.

Data availability statement All data relevant to the study are included in the article or uploaded as supplementary information.

Supplemental material This content has been supplied by the author(s). It has not been vetted by BMJ Publishing Group Limited (BMJ) and may not have been peer-reviewed. Any opinions or recommendations discussed are solely those of the author(s) and are not endorsed by BMJ. BMJ disclaims all liability and responsibility arising from any reliance placed on the content. Where the content includes any translated material, BMJ does not warrant the accuracy and reliability of the translations (including but not limited to local regulations, clinical guidelines, terminology, drug names and drug dosages), and is not responsible for any error and/or omissions arising from translation and adaptation or otherwise.

Open access This is an open access article distributed in accordance with the Creative Commons Attribution Non Commercial (CC BY-NC 4.0) license, which permits others to distribute, remix, adapt, build upon this work non-commercially, and license their derivative works on different terms, provided the original work is properly cited, appropriate credit is given, any changes made indicated, and the use is non-commercial. See: http://creativecommons.org/licenses/by-nc/4.0/.

\section{ORCID iD}

Bodrun Naher Siddiquea http://orcid.org/0000-0002-9224-113X

\section{REFERENCES}

1 Morens DM, Folkers GK, Fauci AS. The challenge of emerging and re-emerging infectious diseases. Nature 2004;430:242-9.

2 World Health Organization. Coronavirus disease (COVID-19) pandemic situation report, 2020. Available: https://www.who.int/ emergencies/diseases/novel-coronavirus-2019 [Accessed 03 Dec 2020].

3 Wu C, Chen X, Cai Y, et al. Risk factors associated with acute respiratory distress syndrome and death in patients with coronavirus disease 2019 pneumonia in Wuhan, China. JAMA Intern Med 2020;180:934-43.
4 Caputo ND, Strayer RJ, Levitan R. Early Self-Proning in awake, Non-intubated patients in the emergency department: a single ED's experience during the COVID-19 pandemic. Acad Emerg Med 2020;27:375-8.

5 Wang W, Wu Q, Yang J, et al. Global, regional, and national estimates of target population sizes for covid-19 vaccination: descriptive study. BMJ 2020;371:m4704.

6 World Health Organization. Monitoring vaccine wastage at country level: guidelines for programme managers. WHO, 2005.

7 Johnson NF, Velásquez N, Restrepo NJ, et al. The online competition between pro- and anti-vaccination views. Nature 2020;582:1-4.

8 Sallam M. COVID-19 vaccine hesitancy worldwide: a Concise systematic review of vaccine acceptance rates. Vaccines 2021;9:160.

9 Razai MS, Doerholt K, Ladhani S, et al. Coronavirus disease 2019 (covid-19): a guide for UK GPs. BMJ 2020;368:m800.

10 Organization WH. Advice on the use of masks in the context of COVID-19: interim guidance. World Health Organization, 2020.

11 Al-Hanawi MK, Angawi K, Alshareef N, et al. Knowledge, attitude and practice toward COVID-19 among the public in the Kingdom of Saudi Arabia: a cross-sectional study. Front Public Health 2020;8:217.

12 Sohrabi C, Alsafi Z, O'Neill N, et al. World Health organization declares global emergency: a review of the 2019 novel coronavirus (COVID-19). Int J Surg 2020;76:71-6.

13 Sarria-Guzmán Y, Fusaro C, Bernal JE, et al. Knowledge, attitude and practices (KAP) towards COVID-19 pandemic in America: a preliminary systematic review. J Infect Dev Ctries 2021;15:9-21.

14 Bekele F, Sheleme T, Fekadu G, et al. Patterns and associated factors of COVID-19 knowledge, attitude, and practice among general population and health care workers: a systematic review. SAGE Open Med 2020;8:205031212097072.

15 Moher D, Shamseer L, Clarke M, et al. Preferred reporting items for systematic review and meta-analysis protocols (PRISMA-P) 2015 statement. Syst Rev 2015;4:1.

16 Stroup DF, Berlin JA, Morton SC, et al. Meta-Analysis of observational studies in epidemiology: a proposal for reporting. meta-analysis of observational studies in epidemiology (moose) group. JAMA 2000;283:2008-12.

17 National Heart Lung and Blood Institute (NHLBI). Quality assessment tool for observational studies, 2016. Available: https:// www.nhlbi.nih.gov/health-topics/study-quality-assessment-tools

18 Nyaga VN, Arbyn M, Aerts M. Metaprop: a Stata command to perform meta-analysis of binomial data. Arch Public Health 2014;72:39.

19 Deeks JJ HJ, Altman DG. Chapter 10: Analysing data and undertaking meta-analyses. In: Higgins JPT, Thomas J, Chandler $\mathrm{J}$, et al, eds. Cochrane Handbook for systematic reviews of interventions Cochrane, 2021.

20 Higgins JPT, Thompson SG, Deeks JJ, et al. Measuring inconsistency in meta-analyses. BMJ 2003;327:557-60.

21 The World Bank. World bank country classification by income level, 2020. Available: https://data.worldbank.org/country

22 Egger M, Davey Smith G, Schneider M, et al. Bias in meta-analysis detected by a simple, graphical test. BMJ 1997;315:629-34.

23 Abdelhafiz AS, Mohammed Z, Ibrahim ME, et al. Knowledge, Perceptions, and Attitude of Egyptians Towards the Novel Coronavirus Disease (COVID-19). J Community Health 2020;45:881-90.

24 Adesegun OA, Binuyo T, Adeyemi O, et al. The COVID-19 crisis in sub-Saharan Africa: knowledge, attitudes, and practices of the Nigerian public. Am J Trop Med Hyg 2020;103:1997-2004.

25 Afzal MS, Khan A, Qureshi UUR, et al. Community-Based assessment of knowledge, attitude, practices and risk factors regarding COVID-19 among Pakistanis residents during a recent outbreak: a cross-sectional survey. J Community Health 2021;46:476-86.

26 Alabed AAA, Elengoe A, Anandan ES, et al. Recent perspectives and awareness on transmission, clinical manifestation, quarantine measures, prevention and treatment of COVID-19 among people living in Malaysia in 2020. Z Gesundh Wiss 2020:1-10.

27 Alahdal H, Basingab F, Alotaibi R. an analytical study on the awareness, attitude and practice during the COVID-19 pandemic in Riyadh, Saudi Arabia. Journal of Infection and Public Health 2020.

28 Alhazmi A, Ali MHM, Mohieldin A, et al. Knowledge, attitudes and practices among people in Saudi Arabia regarding COVID-19: a cross-sectional study. J Public health Res 2020;9:345-53.

29 Alobuia WM, Dalva-Baird NP, Forrester JD, et al. Racial disparities in knowledge, attitudes and practices related to COVID-19 in the USA. J Public Health 2020;42:470-8. 
30 Amalakanti S, Raman Arepalli KV, Koppolu RK. Gender and occupation predict coronavirus disease 2019 knowledge, attitude and practices of a cohort of a South Indian state population. Indian $J$ Med Microbiol 2020;38:144-56.

31 Aqeel U, Ali MD, Iqbal Z. Knowledge, attitudes, and practices toward coronavirus disease-19 infection among residents of Delhi NCR, India: a cross-sectional survey based study. Asian Journal of Pharmaceutical and Clinical Research 2020;13:110-6.

32 Ashiq K, Ashiq S, Bajwa MA, et al. Knowledge, attitude and practices among the inhabitants of Lahore, Pakistan towards the COVID-19 pandemic: an immediate online based cross-sectional survey while people are under the lockdown. Bangladesh Journal of Medical Science 2020;19:S69-76.

33 Azlan AA, Hamzah MR, Sern TJ, et al. Public knowledge, attitudes and practices towards COVID-19: A cross-sectional study in Malaysia. PLoS One 2020;15:e0233668

34 Bates BR, Moncayo AL, Costales JA, et al. Knowledge, attitudes, and practices towards COVID-19 among Ecuadorians during the outbreak: an online cross-sectional survey. $J$ Community Health 2020:45:1158-67.

35 Clements JM. Knowledge and behaviors toward COVID-19 among US residents during the early days of the pandemic: cross-sectional online questionnaire. JMIR Public Health Surveill 2020;6:e19161.

36 Czeisler Mark É, Tynan MA, Howard ME, et al. Public Attitudes, Behaviors, and Beliefs Related to COVID-19, Stay-at-Home Orders, Nonessential Business Closures, and Public Health Guidance United States, New York City, and Los Angeles, May 5-12, 2020. MMWR Morb Mortal Wkly Rep 2020;69:751.

37 Domiati S, Itani M, Itani G. Knowledge, attitude, and practice of the Lebanese community toward COVID-19. Front Med 2020;7:542.

38 Ehoche EE, Adejoh J, Idoko J, et al. Preliminary survey on knowledge, attitudes, and practices about the COVID-19 pandemic among residents in North central Nigeria. Borneo Journal of Pharmacy 2020;3:121-9.

39 Elayeh E, Aleidi SM, Ya'acoub R, et al. Before and after case reporting: a comparison of the knowledge, attitude and practices of the Jordanian population towards COVID-19. PLoS One 2020;15:e0240780.

40 Ferdous MZ, Islam MS, Sikder MT, et al. Knowledge, attitude, and practice regarding COVID-19 outbreak in Bangladesh: an onlinebased cross-sectional study. PLoS One 2020;15:e0239254.

41 Geldsetzer P. Use of rapid online surveys to assess people's perceptions during infectious disease outbreaks: a cross-sectional survey on COVID-19. J Med Internet Res 2020;22:e18790.

42 Ghazi HF, Taher TMJ, AbdalQader MA, et al. Knowledge, attitude, and practice regarding coronavirus disease-19: population-based study in Iraq. Open Access Maced J Med Sci 2020;8:137-41.

43 Hager E, Odetokun IA, Bolarinwa O, et al. Knowledge, attitude, and perceptions towards the 2019 coronavirus pandemic: a bi-national survey in Africa. PLoS One 2020;15:e0236918.

$44 \mathrm{Haq}$ SU, Shahbaz P, Boz I. Knowledge, behavior and precautionary measures related to COVID-19 pandemic among the general public of Punjab Province, Pakistan. J Infect Dev Ctries 2020;14:823-35.

45 Hayat K, Rosenthal M, Xu S, et al. View of Pakistani residents toward coronavirus disease (COVID-19) during a rapid outbreak: a rapid online survey. Int J Environ Res Public Health 2020;17:12.

46 Hezima A, Aljafari A, Aljafari A, et al. Knowledge, attitudes, and practices of Sudanese residents towards COVID-19. East Mediterr Health J 2020;26:646-51.

47 Honarvar B, Lankarani KB, Kharmandar A, et al. Knowledge, attitudes, risk perceptions, and practices of adults toward COVID-19: a population and field-based study from Iran. Int $J$ Public Health 2020;65:731-9.

48 Hossain MA, Jahid MIK, Hossain KMA, et al. Knowledge, attitudes, and fear of COVID-19 during the rapid rise period in Bangladesh. PLoS One 2020;15:e0239646.

49 Hossain MJ, Kuddus MR, Rahman SMA. Knowledge, attitudes, and behavioral responses toward COVID-19 during early phase in Bangladesh: a questionnaire-based study. Asia Pac J Public Health 2021:33:1010539520977328:141-4.

50 Islam S, Emran GI, Rahman E, et al. Knowledge, attitudes and practices associated with the COVID-19 among slum dwellers resided in Dhaka City: a Bangladeshi Interview-Based survey. $J$ Public Health 2021;43:13-25.

51 Kasemy ZA, Bahbah WA, Zewain SK, et al. Knowledge, attitude and practice toward COVID-19 among Egyptians. J Epidemiol Glob Health 2020;10:378-85.

52 Kebede Y, Yitayih Y, Birhanu Z, et al. Knowledge, perceptions and preventive practices towards COVID-19 early in the outbreak among Jimma University medical center visitors, Southwest Ethiopia. PLoS One 2020;15:e0233744.
53 Khaled A, Siddiqua A, Makki S. The knowledge and attitude of the community from the aseer region, Saudi Arabia, toward covid-19 and their precautionary measures against the disease. Risk Manag Healthc Policy 2020;13:1825-34.

54 Carsi Kuhangana T, Kamanda Mbayo C, Pyana Kitenge J, et al. COVID-19 pandemic: knowledge and attitudes in public markets in the former Katanga Province of the Democratic Republic of Congo. Int J Environ Res Public Health 2020;17:1-16.

55 La Torre G, Lia L, Dorelli B, et al. How much do young Italians know about COVID-19 and what are their attitudes toward SARS-CoV-2? results of a cross-sectional study. Disaster Med Public Health Prep 2021:15:e15-21.

56 Lau LL, Hung N, Go DJ, et al. Knowledge, attitudes and practices of COVID-19 among income-poor households in the Philippines: a cross-sectional study. J Glob Health 2020:10:1-11.

57 Parsons Leigh J, Fiest K, Brundin-Mather R, et al. A national crosssectional survey of public perceptions of the COVID-19 pandemic: self-reported beliefs, knowledge, and behaviors. PLoS One 2020;15:e0241259.

58 Narayana G, Pradeepkumar B, Ramaiah JD, et al. Knowledge, perception, and practices towards COVID-19 pandemic among general public of India: a cross-sectional online survey. Curr Med Res Pract 2020;10:153-9.

59 Naser AY, Dahmash EZ, Alwafi H. Knowledge and practices towards COVID-19 during its outbreak: a multinational cross-sectional study. medRxiv2020.

60 Ngwewondo A, Nkengazong L, Ambe LA, et al. Knowledge, attitudes, practices of/towards COVID 19 preventive measures and symptoms: a cross-sectional study during the exponential rise of the outbreak in Cameroon. PLoS Negl Trop Dis 2020;14:e0008700.

61 Rahman A, Sathi NJ. Knowledge, attitude, and preventive practices toward COVID-19 among Bangladeshi Internet users. Electronic Journal of General Medicine 2020;17:em245.

62 Rahman SMM, Akter A, Mostari KF, et al. Assessment of knowledge, attitudes and practices towards prevention of coronavirus disease (COVID-19) among Bangladeshi population. Bangladesh Med Res Counc Bull 2020;46:73-82.

63 Sari DK, Amelia R, Dharmajaya R, et al. Positive Correlation Between General Public Knowledge and Attitudes Regarding COVID-19 Outbreak 1 Month After First Cases Reported in Indonesia. J Community Health 2021;46:182-9.

64 Seale H, Heywood AE, Leask J, et al. COVID-19 is rapidly changing: examining public perceptions and behaviors in response to this evolving pandemic. PLoS One 2020;15:e0235112.

65 Vandhana S, Srinivasan V. Knowledge, attitudes, practices and psychological response towards COVID-19 pandemic among general public in India. International Journal of Research in Pharmaceutical Sciences2020;11:892-900.

66 Wong CL, Chen J, Chow KM, et al. Knowledge, attitudes and practices towards COVID-19 amongst ethnic minorities in Hong Kong. Int J Environ Res Public Health 2020;17:7878.

67 Yang K, Liu H, Ma L, et al. Knowledge, attitude and practice of residents in the prevention and control of COVID-19: an online questionnaire survey. J Adv Nurs 2021;77:1839-55.

68 Yue S, Zhang J, Cao M. Knowledge, attitudes and practices of COVID-19 among urban and rural residents in China: a crosssectional study. J Community Health 2020;05.

69 Zaid AA, Barakat M, Al-Qudah RA. Knowledge and awareness of community toward COVID-19 in Jordan: a cross-sectional study. Systematic Reviews in Pharmacy 2020;11:135-42.

70 Zhong B-L, Luo W, Li H-M, et al. Knowledge, attitudes, and practices towards COVID-19 among Chinese residents during the rapid rise period of the COVID-19 outbreak: a quick online crosssectional survey. Int J Biol Sci 2020;16:1745-52.

$71 \mathrm{Gao} \mathrm{H}, \mathrm{Hu}$ R, Yin L, et al. Knowledge, attitudes and practices of the Chinese public with respect to coronavirus disease (COVID-19): an online cross-sectional survey. BMC Public Health 2020;20:1816.

72 Abbasi-Kangevari M, Kolahi A-A, Ghamari S-H, et al. Public knowledge, attitudes, and practices related to COVID-19 in Iran: questionnaire study. JMIR Public Health Surveill 2021;7:e21415.

73 Al Ahdab S. A cross-sectional survey of knowledge, attitude and practice (KAP) towards COVID-19 pandemic among the Syrian residents. BMC Public Health 2021;21:296.

74 Al-Hussami M, El-Hneiti M, Bani Salameh A, et al. Knowledge, attitudes, and behavior toward COVID-19 among Jordanian residents during the quarantine period of the COVID-19 pandemic: a national survey. Disaster Med Public Health Prep 2021:1-9.

75 Banik R, Rahman M, Sikder MT. Knowledge, attitudes, and practices related to the COVID-19 pandemic among Bangladeshi youth: a web-based cross-sectional analysis. Journal of Public Health 2021. 
76 Bates BR, Tami A, Carvajal A, et al. Knowledge, attitudes, and practices towards COVID-19 among Venezuelans during the 2020 epidemic: an online cross-sectional survey. PLoS One 2021;16:e0249022.

77 Bates BR, Villegas Botero A, Grijalva MJ. Knowledge, attitudes, and practices towards COVID-19 among Colombians during the outbreak: an online cross-sectional survey. $\mathrm{J}$ Commun Healthc 2020;13:262-70.

78 Bekele D, Tolossa T, Tsegaye R, et al. The knowledge and practice towards COVID-19 pandemic prevention among residents of Ethiopia. An online cross-sectional study. PLoS One 2021;16:e0234585

79 Desalegn Z, Deyessa N, Teka B, et al. COVID-19 and the public response: knowledge, attitude and practice of the public in mitigating the pandemic in Addis Ababa, Ethiopia. PLoS One 2021;16:e0244780.

80 Habib MA, Dayyab FM, Iliyasu G, et al. Knowledge, attitude and practice survey of COVID-19 pandemic in northern Nigeria. PLOS One 2021;16:e0245176.

81 Ladiwala ZFR, Dhillon RA, Zahid I, et al. Knowledge, attitude and perception of Pakistanis towards COVID-19; a large cross-sectional survey. BMC Public Health 2021;21:21.

82 Lee M, Kang B-A, You M. Knowledge, attitudes, and practices (KAP) toward COVID-19: a cross-sectional study in South Korea. BMC Public Health 2021;21:295.

83 Li Y, Liu G, Egolet RO, et al. Knowledge, attitudes, and practices related to COVID-19 among Malawi adults: a community-based survey. Int J Environ Res Public Health 2021;18:13

84 Masoud AT, Zaazouee MS, Elsayed SM, et al. KAP-COVID a multinational survey of the levels and determinants of public knowledge, attitudes and practices towards COVID-19. BMJ Open 2021;11:e043971

85 Mohamed AAO, Elhassan EAM, Mohamed AO, et al. Knowledge, attitude and practice of the Sudanese people towards COVID-19: an online survey. BMC Public Health 2021;21:274.

86 Molla KA, Abegaz SB. Community knowledge, attitude and practices to SARS-CoV-2 disease 2019 (COVID-19): a crosssectional study in Woldia town, northeast Ethiopia. PLoS One 2021;16:e0250465

87 Mouchtouri VA, Agathagelidou E, Kofonikolas K, et al. Nationwide survey in Greece about knowledge, risk perceptions, and preventive behaviors for COVID-19 during the general lockdown in April 2020. Int J Environ Res Public Health 2020;17:8854.

88 Nakhostin-Ansari A, Aghajani F, Khonji MS, et al. Did Iranians respect health measures during Nowruz holidays? A study on Iranians' knowledge, attitude and practice toward COVID-19. J Prev Med Hyg 2020;61:E501-7.

89 Naqid IA, Abdi BA, Ahmed RH. Public knowledge, attitudes, and practices regarding the coronavirus disease pandemic: a crosssectional study in the Kurdistan region, Iraq. European Journal of Molecular and Clinical Medicine 2021;8:1148-61.

90 Amer SA DIO. Egyptian public's knowledge, attitudes, perceptions, and practices toward covid-19 infection and their determinants. A cross-sectional study, 2020. Open Access Macedonian Journal of Medical Sciences 2021:9:250-9.

91 Okello G, Izudi J, Teguzirigwa S, et al. Findings of a cross-sectional survey on knowledge, attitudes, and practices about COVID-19 in Uganda: implications for public health prevention and control measures. Biomed Res Int 2020;2020:1-8.

92 Paul A, Sikdar D, Hossain MM, et al. Knowledge, attitudes, and practices toward the novel coronavirus among Bangladeshis: implications for mitigation measures. PLoS One 2020;15:e0238492.

93 Qalati SA, Ostic D, Fan M, et al. The general public knowledge, attitude, and practices regarding COVID-19 during the Lockdown in Asian developing countries. Int Q Community Health Educ 2021:272684X211004945

94 Reuben RC, Danladi MMA, Saleh DA, et al. Knowledge, attitudes and practices towards COVID-19: an epidemiological survey in north-central Nigeria. J Community Health 2021;46:457-70.

95 Saeed BQ, Al-Shahrabi R, Bolarinwa OA. Socio-Demographic correlate of knowledge and practice toward COVID-19 among people living in Mosul-Iraq: a cross-sectional study. PLoS One 2021;16:e0249310.
96 Sakr S, Ghaddar A, Sheet I, et al. Knowledge, attitude and practices related to COVID-19 among young Lebanese population. BMC Public Health 2021;21:653.

97 Sengeh $\mathrm{P}$, Jalloh MB, Webber N, et al. Community knowledge, perceptions and practices around COVID-19 in Sierra Leone: a nationwide, cross-sectional survey. BMJ Open 2020;10:e040328.

98 Shahabi N, Kamalzadeh Takhti $\mathrm{H}$, Hassani Azad M, et al. Knowledge, attitude, and preventive behaviors of Hormozgan residents toward COVID-19, one month after the epidemic in Iran. $Z$ Gesundh Wiss 2021:1-12.

99 Sulistyawati S, Rokhmayanti R, Aji B, et al. Knowledge, attitudes, practices and information needs during the covid-19 pandemic in Indonesia. Risk Manag Healthc Policy 2021;14:163-75.

100 Taddese AA, Azene ZN, Merid MW, et al. Knowledge and attitude of the communities towards COVID-19 and associated factors among Gondar City residents, Northwest Ethiopia: a community based cross-sectional study. PLoS One 2021;16:e0248821.

101 Takoudjou Dzomo GR, Bernales M, López R, et al. Knowledge, attitudes and practices regarding COVID-19 in N'Djamena, Chad. $J$ Community Health 2021;46:259-66.

102 Tawalbeh LI, Al-Smadi AM, Ashour A, et al. Public knowledge, attitudes and practice about COVID-19 pandemic. J Public Health Africa 2021.

103 Van Nhu H, Tuyet-Hanh TT, Van NTA, et al. Knowledge, attitudes, and practices of the Vietnamese as key factors in controlling COVID-19. J Community Health 2020;45:1263-9.

104 Xu Y, Lin G, Spada C, et al. Public knowledge, attitudes, and practices behaviors towards coronavirus disease 2019 (COVID-19) during a national Epidemic-China. Front Public Health 2021;9:638430.

105 Yoseph A, Tamiso A, Ejeso A. Knowledge, attitudes, and practices related to COVID-19 pandemic among adult population in Sidama regional state, southern Ethiopia: a community based crosssectional study. PLoS One 2021:16:e0246283.

106 Rukmanee N, Yimsamran S, Rukmanee P. Knowledge, attitudes and practices (KAP) regarding influenza $A(\mathrm{H} 1 \mathrm{~N} 1)$ among a population living along Thai-Myanmar border, Ratchaburi Province, Thailand. Southeast Asian J Trop Med Public Health 2014;45:825.

107 Tan X, Li S, Wang C, et al. Severe acute respiratory syndrome epidemic and change of people's health behavior in China. Health Educ Res 2004;19:576-80.

108 ALdowyan N, Abdallah AS, El-Gharabawy R. Knowledge, attitude and practice (KAP) study about middle East respiratory syndrome coronavirus (MERS-CoV) among population in Saudi Arabia. Int Arch Med 2017:10.

109 Moran KR, Del Valle SY. A meta-analysis of the association between gender and protective behaviors in response to respiratory epidemics and pandemics. PLoS One 2016;11:e0164541.

110 Hutchins SS, Fiscella K, Levine RS, et al. Protection of racial/ethnic minority populations during an influenza pandemic. Am J Public Health 2009;99 Suppl 2:S261-70.

111 Centers for Disease Control and Prevention. Information on 2009 H1N1 impact by race and ethnicity. Available: https://www.cdc.gov/ h1n1flu/race_ethnicity_qa.htm [Accessed 19 Jan 2021]

112 Morgul E, Bener A, Atak M, et al. COVID-19 pandemic and psychological fatigue in turkey. Int $J$ Soc Psychiatry 2021;67:128-35.

113 Lin Y, Huang L, Nie S, et al. Knowledge, attitudes and practices (KAP) related to the pandemic (H1N1) 2009 among Chinese general population: a telephone survey. BMC Infect Dis 2011;11:128.

114 Kawanpure $\mathrm{H}$, Ugargol AR, Padmanabha B. A study to assess knowledge, attitude and practice regarding swine flu. Int $J$ Health Sci Res 2014;4:6-11.

115 Kamate SK, Agrawal A, Chaudhary H, et al. Public knowledge, attitude and behavioural changes in an Indian population during the influenza A ( $11 \mathrm{~N} 1)$ outbreak. The Journal of Infection in Developing Countries 2010;4:007-14.

116 Tolvanen M, Lahti S, Miettunen J, et al. Relationship between oral health-related knowledge, attitudes and behavior among 15-16-year-old adolescents: a structural equation modeling approach. Acta Odontol Scand 2012;70:169-76.

117 Feng S, Shen C, Xia N, et al. Rational use of face masks in the COVID-19 pandemic. Lancet Respir Med 2020;8:434-6. 